\title{
Thermal properties of porcelain reinforced polyester resin composites
}

\author{
R. Sultana ${ }^{1}$, R. Akter ${ }^{2}$, M. R. Qadir $^{3}$, M. A. Gafur ${ }^{3}$ and M. Z. Alam ${ }^{2 *}$ \\ ${ }^{1}$ Centre for Advanced Research in Sciences (CARS), University of Dhaka, Dhaka, Bangladesh \\ ${ }^{2}$ Department of Applied Chemistry and Chemical Engineering, University of Dhaka, Dhaka, Bangladesh \\ ${ }^{3}$ PP \& PDC, Bangladesh Council of Scientific and Industrial Research (BCSIR), Dhaka, Bangladesh
}

\begin{abstract}
Porcelain reinforced polyester resin composites (PPCs) having different compositions have been prepared by compression molding. Thermal properties of PPCs were studied by means of TG-DTA and TMA. The influence of porcelain content on thermal properties of PPCs was studied in detail. Thermal conductivities of PPCs decreased from $0.00068 \mathrm{cal} / \mathrm{cm} \mathrm{sec}{ }^{\circ} \mathrm{C}$ to $0.00030 \mathrm{cal} / \mathrm{cm} \mathrm{sec}^{\circ} \mathrm{C}$ by the addition of porcelain from 10 to $60 \%$. The results of this study reveal their good thermal stabilities. The $50 \%$ degradation temperature of pure Polyester resin was $401.5^{\circ} \mathrm{C}$, but that of the PPC-1, PPC-2 and PPC-4 were $406.3^{\circ} \mathrm{C}, 407.8^{\circ} \mathrm{C}$, and $417.3^{\circ} \mathrm{C}$ respectively. The morphology of the composites was studied with scanning electron microscopy (SEM).
\end{abstract}

Keywords: Composites; Polyester resin; Thermo-mechanical analysis; Thermo-gravimetric analysis; Thermal conductivity

\section{Introduction}

Composites consist of one or more discrete phases embedded in a continuous phase to produce a multiphase material which possesses superior properties that are not obtainable with any of the constituent materials acting alone. Recently composite materials have been of interest because of their wide applications in many fields such as civil, industrial, military, space craft, automobiles, packaging and biomedical applications mainly because of their excellent thermo-mechanical properties (Kafi et al., 2006; Khan et al., 2010; Bledzki and Gassan, 1999; Hattum et al. 2011; Singh et al. 2012). Composites have already proven their worth as weight saving materials. The current challenge is to make them durable in tough conditions to replace other materials and also to make them cost effective.

Polyesters are one of the most versatile synthetic copolymers commercially available and display a wide variety of properties and applications. Since 1930, unsaturated polyester resin has been used remarkably for wide range of applications making them a thermosetting system of major importance (Frodet and Arland, 1989; Mark et al., 1970). The advantages of unsaturated polyester are its dimensional stability, affordable cost, ease in handling, processing and fabricating. This resin is probably the best value for a balance between performance and structural capabilities (Mathews and Rawlings, 1994;
Tuttle, 2004). These resins are compounded with various fillers, reinforcement and cured by using free radical initiators to yield thermo-set articles having a wide range of chemical and mechanical properties (Boenig, 1964). This versatility in the properties of the final thermo-set product associated with comparatively low cost has renewed the interest in these resins as an important matrix material for the wide range of applications.

Composites comprise strong load carrying material known as reinforcement imbedded in weaker material known as matrix (Lilholt and Lawther, 2000). Reinforcement provides strength and rigidity, helping to support structural load. The matrix or binder (organic or inorganic) maintains the position and orientation of the reinforcement. Porcelain is a ceramic material made by heating clay in the form of kaolin. It controls viscosity, promotes flow, and improves resistance to cracking in molded parts. Properties associated with porcelain include low permeability and elasticity; considerable strength, hardness, toughness, whiteness, translucency, and resonance; and a high resistance to chemical attack and thermal shock. Whaling et al., studied the novel talc-filled biodegradable bacterial polyester composites (Whaling et al., 2006). Talc-filled composites of polyester, i.e. poly (3-hyroxybutyrate-co-3-hydroxyvalerate), PHBV, were prepared by extrusion followed by an injection molding

\footnotetext{
* Corresponding author e-mail: zahangir@du.ac.bd
} 
process. The effects of the talc weight content (15-50 wt \%) on various thermo-mechanical properties of the PHBV-based composites were investigated. The storage modulus (E) and heat defection temperature (HDT) of the PHBV composite were found to increase when the composites were reinforced with talc particles. The coefficient of linear thermal expansion (CLTE) of PHBV was reduced by $56 \%$ for the composite reinforced with a talc content of $50 \mathrm{wt} \%$.

Generally polymer/clay composites are thermally more stable than pure polymers (Ray and Bousima, 2005; Becker et al., 2004; Zanetti et al., 2004). This is due to the incorporation of clay fillers into the polymer matrices results to the improvement of their thermal stability. Clay minerals are inorganic materials and are almost stable in the temperature ranges that organic polymers are degraded into volatile compounds. This paper describes the thermal characteristics of PPCs prepared in this study as well as the effects of porcelain contents on their properties.

\section{Materials and methods}

The chief raw materials used for the specimen preparation are porcelain and polyester resin. Porcelain is collected from US and polyester is purchased from the local market, Bangladesh. Composites of different composition ranging from $10 \%$ to $60 \mathrm{wt} \%$ porcelain with respect to the weight of unsaturated polyester resin. At first porcelain was dried at $100^{\circ} \mathrm{C}$ for 24 hours in a preheated oven. Required amounts of porcelain and polyester resin were taken in a bowl and were mixed very properly. Methyl ethyl ketone peroxide (MEKP) at an amount of $1.5 \mathrm{wt} \%$ of polyester resin was used as a hardener since Ross et al. reported that MEKP concentrations in excess of $3 \%$ result in degradation of mechanical properties as well as glass transition temperature (Ross et al., 2007). The mixture was then poured into the closed mould and kept it 4-5 hours for drying. After drying the composite is released from the mould with Karl Kolb Press Machine by applying pressure. Four samples of porcelain and polyester composites in the ratio of 10:90, 30:70, 40:60, 60:40 were prepared and were termed as PPC-1, PPC-2, PPC-3 and PPC-4, respectively.

Thermal properties of the porcelain/polyester composites were studied with TG-DTA and TMA. Thermomechanical analyses (TMA) of the composites were determined by TMA/SS 6300 system, Seiko Instrument, Inc. Japan. According to ASTM method C 201 the thermal conductivity of the composites was measured. All the experiments were performed in the nitrogen atmosphere. Samples weights were $10-15 \mathrm{~g}$, and heating rate was $20^{\circ} \mathrm{C} / \mathrm{min}$ within the temperature range of room temperature to $600{ }^{\circ} \mathrm{C}$. The morphology of the composites was studied with Scanning Electron Microscope (JEOL JSM-6490 LA, Japan). The non-conducting surface of the composites was coated with platinum in auto fine coater (model JEOL JFC-1600, Japan) before subjected to SEM.

\section{Results and discussion}

\section{Thermo-mechanical analyses of PPCs}

Thermo-mechanical analyses of PPCs were carried out and the results are shown in Fig. 1 and Table I. The data revealed that thermal expansion coefficient of PPCs decreased with an increase in porcelain content. It is assumed that thermal expansion coefficients of PPCs are lower than that of polyester resin due to an increase in the bond energy between polyester resin and porcelain which possess higher hardness (Frodet and Arland, 1989).

\section{Table I. Thermal Expansion coefficient of PPCs}

\begin{tabular}{llll}
\hline & \multicolumn{3}{l}{ Thermal Expansion coefficients } \\
& $1^{\text {st }}$ stage & $2^{\text {nd }}$ stage & $3^{\text {rd }}$ stage \\
\hline Polyester resin & $1.45482 \mathrm{E}^{-4}$ & $8.75663 \mathrm{E}^{-5}$ & $2.96670 \mathrm{E}^{-4}$ \\
PPC-1 & $1.830363 \mathrm{E}^{-4}$ & $1.300152 \mathrm{E}^{-3}$ & $2.533283 \mathrm{E}^{-4}$ \\
PPC-2 & $1.658676 \mathrm{E}^{-4}$ & $8.075093 \mathrm{E}^{-4}$ & $2.124769 \mathrm{E}^{-4}$ \\
PPC-3 & $1.354480 \mathrm{E}^{-4}$ & $6.389107 \mathrm{E}^{-4}$ & $1.982551 \mathrm{E}^{-4}$ \\
PPC-4 & $1.20016 \mathrm{E}^{-4}$ & $3.606676 \mathrm{E}^{-4}$ & $1.658406 \mathrm{E}^{-4}$ \\
& & & \\
\hline
\end{tabular}

\section{Determination of thermal conductivities of PPCs}

A thin layer of composite was used in this study. Fig. 2 shows thermal conductivities of PPCs as a function of porcelain contents. Thermal conductivities of PPCs decreased from $0.00068 \mathrm{cal} / \mathrm{cm} \mathrm{sec}{ }^{\circ} \mathrm{C}$ to $0.00030 \mathrm{cal} / \mathrm{cm}$ $\sec ^{\circ} \mathrm{C}$ by the addition of porcelain from 10 to $60 \%$. The decrease in thermal conductivity with an increase in porcelain content is in agreement with results reported by Budnikov (1964). It is assumed that with the increase of porosity the mean free path decreased resulting in lower thermal conductivity (Kingery, 1962; Ismail et al., 1999). It is also assumed that lower thermal conductivities of PPCs may also be due to the insulating properties of porcelain and heterogeneity of structure. The low thermal conductivity of these composite will help to prevent heat transfer and consequently to save energy.

\section{Thermo-gravimetric analysis}

Thermal stability of PPCs have been analyzed and compared with that of polyester resin. Thermo-gravimetric 


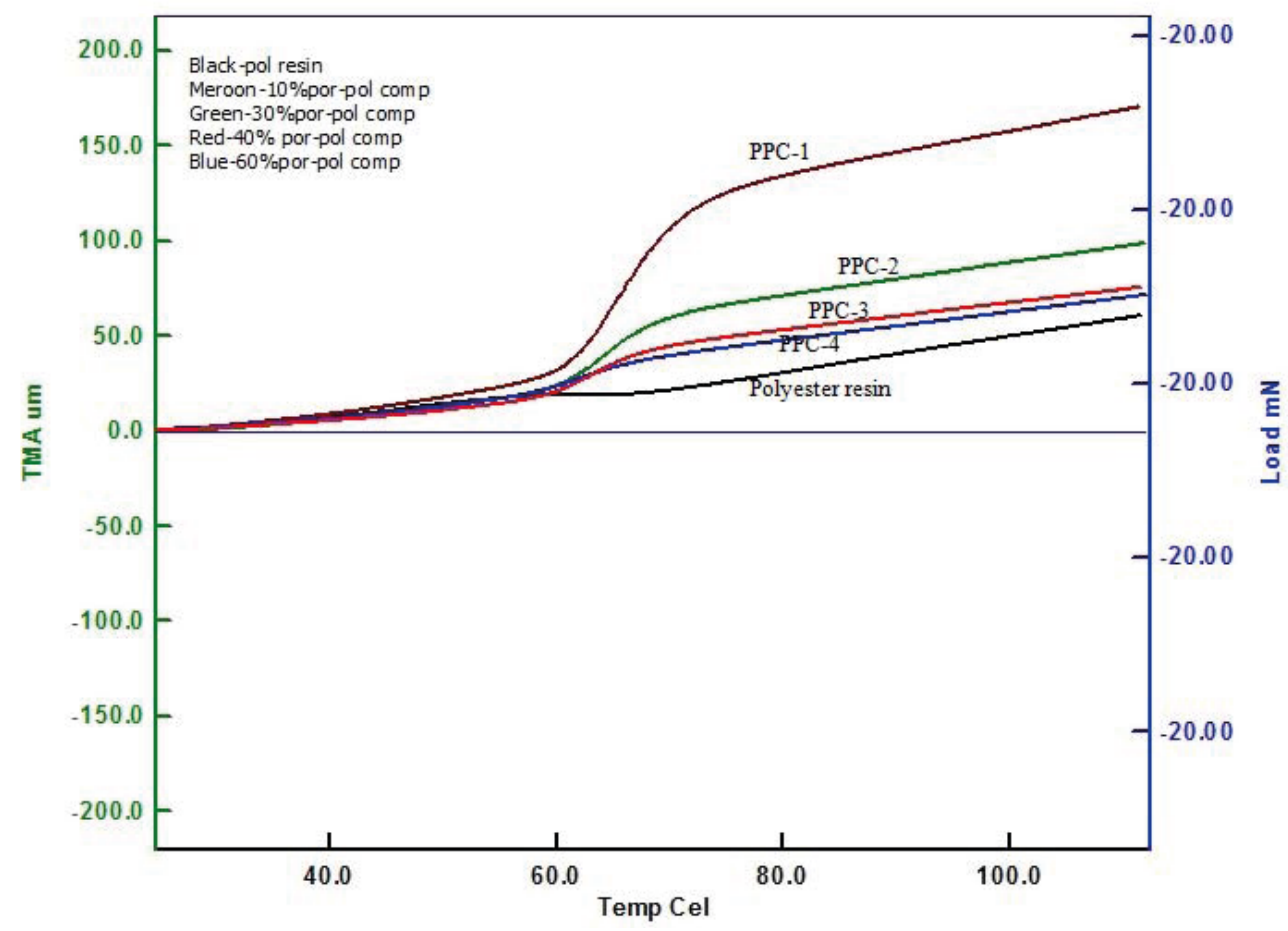

Fig. 1. Thermo-mechanical analysis of PPCs

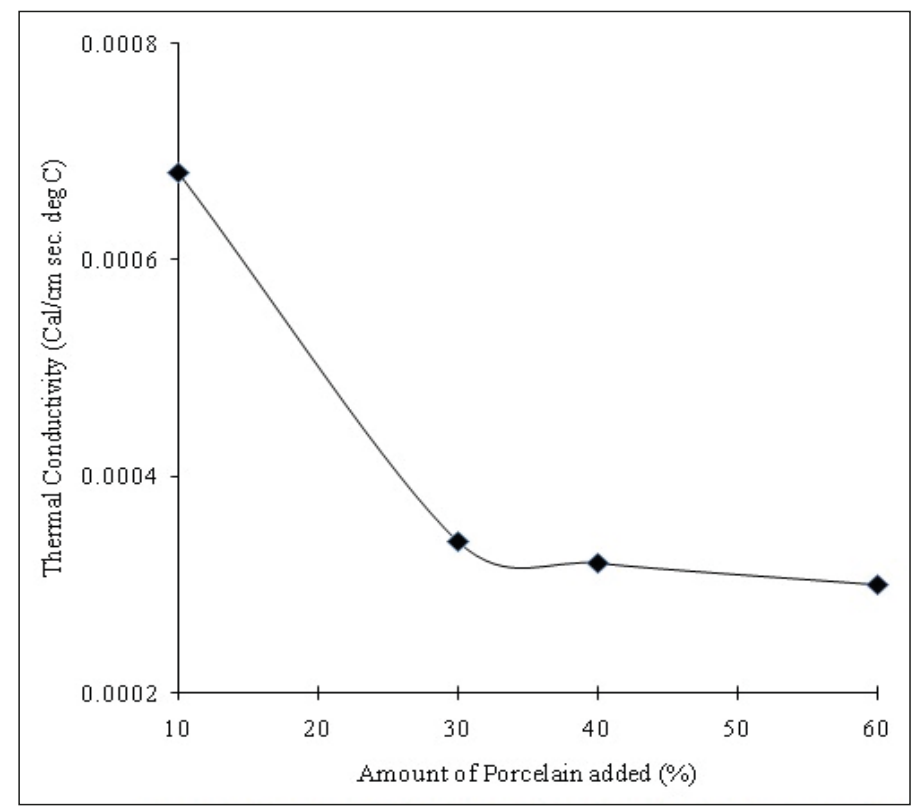

Fig. 2. Thermal conductivity of PPCs as a function of porcelain content 


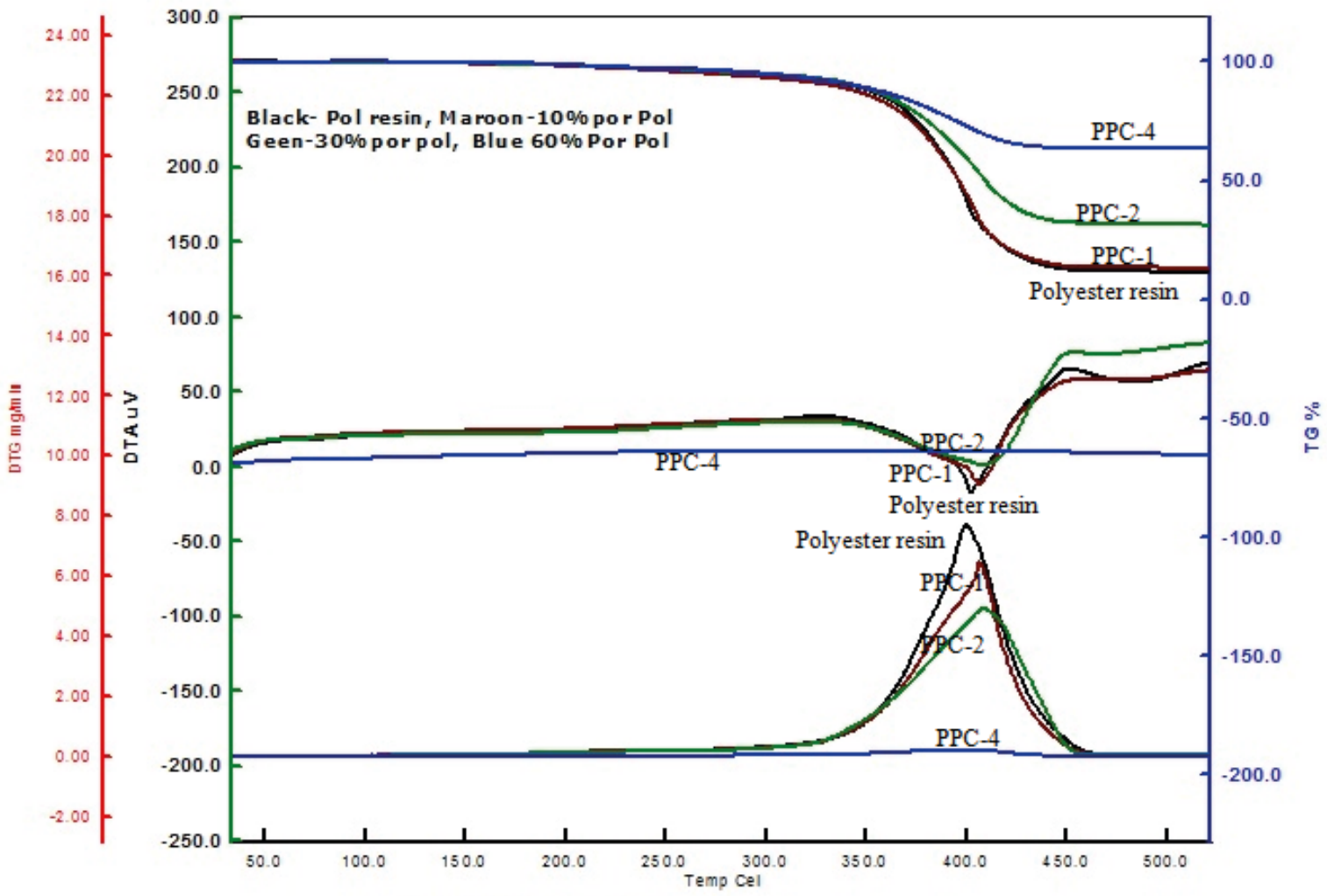

Fig. 3. TG, DTA and DTG of PPCs

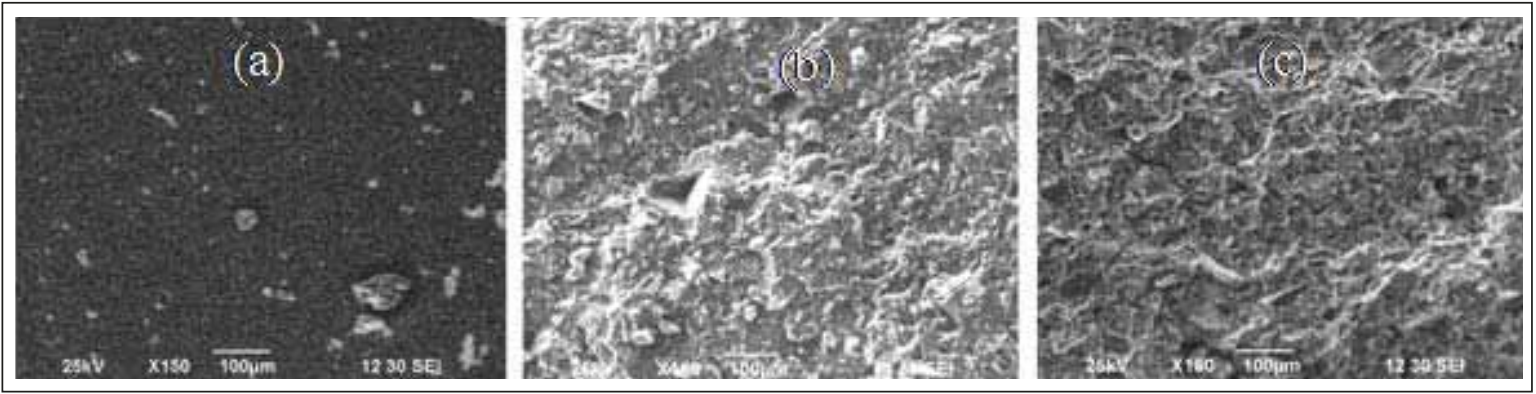

Fig. 4. SEM images of polyester resin (a), PPC-2 (b) and PPC-4 (c) failed in 3-point bending

analysis (TGA) of neat Polyester resin and PPCs were done at a heating rate of $20^{\circ} \mathrm{C} / \mathrm{min}$. Fig. 3 shows the TGA curves of Polyester resin, PPC-1, PPC-2 and PPC-4. The degradation temperature of the Polyester resin has been shifted to higher temperatures with respect to porcelain content. The temperature of the $50 \%$ degradation of PPC has been increased compared to the pure Polyester resin. The $50 \%$ degradation temperature of pure Polyester resin was $401.5^{\circ} \mathrm{C}$, but that of the PPC-1, PPC-2 and PPC-4 were $406.3^{\circ} \mathrm{C}, 407.8^{\circ} \mathrm{C}$, and $417.3^{\circ} \mathrm{C}$ respectively.
The polyester resin sample loses about $3.7 \%$ of its mass at about $250^{\circ} \mathrm{C}$. This effect is due to the lost of moistur. Between $250^{\circ} \mathrm{C}$ and $550^{\circ} \mathrm{C}$ the sample decomposed almost completely i.e. it underwent almost $87 \%$ degradation. As expected PPCs behave similarly except that the effects are reduced in proportion to the filler content. The residues of PPCs were almost similar to their porcelain content. The DTA curves of PPCs show two endothermic peaks of which first one is due to loss 
of moisture and second one is due to degradation. The DTG thermograms of PPCs show that degradation rates of PPCs decreased with porcelain contents.

\section{Scanning electron microscopic observation}

Scanning electron microscopic (SEM) images of polyester resin, PPC-2 and PPC-4 specimen are shown in Fig. 4. No large aggregate was observed and almost a homogeneous distribution of porcelain was found. It is also found that polyester resin exhibits homogenous morphology but upon magnification (X150), voids are seen in polyester resin. The brittle nature of the resin resulted in de-bonding as seen on the micrograph by the resin particles scattered around the porcelain. This indicated the low interfacial toughness of the material due to crack growth under flexural loading.

\section{Conclusion}

The following conclusions may be drawn from this study.

- Thermal expansion coefficients of PPCs are decreased with an increase in porcelain content of the composites due to an increase in the bond energy between polyester resin and porcelain.

- The degradation rate of PPCs was decreased with an increase of porcelain content, i.e. their thermal stabilities were increased.

- Thermal conductivities of PPCs were decreased with the increase of porcelain content due to the insulating property of porcelain.

Thus PPCs prepared in this study can be used for applications such as automobile interior parts, electronic packages, building construction, etc.

\section{References}

Bledzki AK and Gassan J (1999), Composites reinforced with cellulose based fibres, Journal of Progress in Polymer Science 24: 221-274.

Boenig HV (1964), Unsaturated Polyesters In: Structure and Properties, Elsevier, Amsterdam, pp 2-3.

Budnikov PP (1964), The Technology of Ceramics and Refractories, p 365.

Becker O, Varley RJ and Simon GP (2004), Thermal stability and water uptake of high performance epoxy layered silicate nanocomposites, European Polymer Journal 40: 187-195.
Frodet A and Arland P (1989), Unsaturated Polyesters In: Comprehensive Polymer Science, 5(19), Eds. Allen $\mathrm{G}$ and Bevington J C, Pargamon Press, New York, p 331.

Hattum FWJV, Regel F and Labordus M (2011), Cost reduction in manufacturing of aerospace composites, Plastics, Rubber and Composites: Macromolecular Engineering 40: 93-99.

Ismail MR, Ali MAM, El-Milligy AA and Afifi MS (1999), Studies on Sand/Clay unsaturated Polyester Composite, Journal of Applied Polymer Science 72: 1031-1038.

Kafi A, Abedin MZ, Beg M DH, Pickering KL and Khan MA (2006), Study on the Mechanical Properties of Jute/Glass fiber-Reinforced Unsaturated Polyester Hybrid Composites: Effect of surface modification by Ultraviolet Radiation, Journal of Reinforced Plastics and Composites 25(6): 575-588.

Khan RA Sultana S, Khan MN, Khan MA, Shubhra QTH and Noor FG (2010), Mechanical, Degradation and interfacial properties of synthetic degradable fibre reinforced polypropylene composites, Journal of Reinforced Plastics and Composites 29: 466-476.

Kingery WD (1962), The thermal conductivity of ceramic dielectrics In: Progress in Ceramic Sciences, 2, Ed. Burke JE, Pargamon press Inc., New York, p 181.

Lilholt H and Lawther JM (2000), Natural organic fibers: Comprehensive Composite Materials, Eds. Kelly A and Zweben C, Elsevier, New York.

Mark HF Gaylord NG and Bikales NM (1970), Encyclopedia of Polymer Science and Technology, 13, John Wiley and Sons, New York.

Mathews F and Rawlings R (1994), Polymer Matrix Composite In: Composite Materials: Engineering and sciences The Alden Press, Oxford, UK, pp 168-200.

Ross LR, Petersen JA and Lakatos CW (2007), Effects of methyl ethyl ketone peroxide on the performance of cast polymers, Composites Research Journal 1(4): 14-23.

Ray SS and Bousima M (2005), Biodegradable polymers and their layered silicate nanocomposites, in 
greening the $21^{\text {st }}$ century materials world, Progress of Materials Science 50: 962-1079.

Singh S, Kumar P and Jain SK (2012), An experimental and numerical investigation of mechanical properties of glass fiber reinforced polyester composites, Advanced Materials Letters 4(7): 567-572.

Tuttle M (2004), Introduction in Structural analysis of Polymeric Composite Materials, University of Washington, USA, pp 1- 40.
Whaling A, Bhardwaj R and Amar K M (2006), Novel talc-filled biodegradable bacterial polyester composites, Industrial and Engineering Chemistry Research 45(22): 7497-7503.

Zanetti M, Bracco P and Costa L (2004), Thermal degradation behavior of PE/clay nanocomposites, Polymer Degradation and Stability 85: 657-665.

Received: 29 August 2016; Revised: 19 October 2016; Accepted: 28 December 2016. 